\title{
EFFECT OF THERMAL AGING ON STRUCTURAL CHANGES IN P91 AND P5 HEAT RESISTANT STEELS
}

\author{
${ }^{1}$ Vidas MAKAREVIČIUS, ${ }^{1}$ Arūnas BALTUŠNIKAS, ${ }^{1}$ Irena LUKOŠIŪTĖ, ${ }^{1}$ Rita KRIŪKIENĖ, \\ ${ }^{1}$ Albertas GRYBĖNAS
}

${ }^{1}$ Lithuanian Energy Institute, Breslaujos st.3, Kaunas, LT-44403 Lithuania, Vidas.Makarevicius@lei.It

https://doi.org/10.37904/metal.2020.3521

\begin{abstract}
Ferritic-martensitic heat-resistant steels are used for high-temperature service applications in power plants and the petrochemical industry due to its high strength and creep properties at high temperatures. After the long-term operation under, structural changes are taking place, such as coarsening of precipitates and migration of alloying elements within carbides, leading to $\mathrm{M}_{23} \mathrm{C}_{6}$ carbide lattice expansion. The thermal aging effect on the structural changes of $\mathrm{M}_{23} \mathrm{C}_{6}$ carbide for $\mathrm{P} 91(9 \mathrm{Cr}, 1 \mathrm{Mo})$ and $\mathrm{P} 5(5 \mathrm{Cr}, 0.5 \mathrm{Mo})$ steel was investigated after exposure up to 234 days at $700{ }^{\circ} \mathrm{C}$.

The electrochemical extraction method was used to extract carbide precipitates from the steel. The identification of alloy carbides and calculation of the $\mathrm{M}_{23} \mathrm{C}_{6}$ lattice parameter changes have been accomplished by XRD analysis using crystal structure parameters evaluation and Rietveld refinement method. Microstructure evolution and elemental composition changes were studied by SEM-EDX microanalysis. The chromium and molybdenum content in the $\mathrm{M}_{23} \mathrm{C}_{6}$ carbide, determined by SEM/EDX steadily, changes and approaches equilibrium as aging time increases. $X$-ray diffraction measurements show that the $\mathrm{M}_{23} \mathrm{C}_{6}$ carbide crystal lattice parameter increases at high-temperature exposure due to enhanced diffusion of alloying elements from the matrix into a carbide lattice. When the equilibrium for diffusion of the alloying elements is reached, the lattice parameter stops growing. The study shows a significant difference in aging behavior. The obtained knowledge of alloying elements diffusion and $\mathrm{M}_{23} \mathrm{C}_{6}$ lattice parameter transformation changes could be used as an indicator for the assessment of heat resistant steel after the long term service.
\end{abstract}

Keywords: P91 steel, P5 steel, thermal aging, XRD analysis, carbides

\section{INTRODUCTION}

Standard specification ASTM A335 covers several grades of ferritic steels, containing up to $10 \%$ chromium. Steels of this group have good resistance to corrosion and tensile strength at high-temperature service. Grade $\mathrm{P} 91(9 \% \mathrm{Cr}, 1 \% \mathrm{Mo})$ steel is typically used in power stations, whereas grade $\mathrm{P} 5(5 \% \mathrm{Cr}, 0.5 \% \mathrm{Mo})$ is more common for the application in the petrochemical industry.

The addition of alloying elements allows the formation of carbide and carbonitride precipitates inside the matrix and along the grain boundaries. Extensive and relatively coarse $\mathrm{M}_{23} \mathrm{C}_{6}$ carbide precipitates along the grain boundaries. The presence of carbide precipitates plays an important role in the maintenance of proper mechanical properties of heat-resistant steel at elevated temperatures [1].

Long-term service of heat resistant steel at elevated temperature results in a degradation of microstructure as a result of coarsening of both grains and carbide precipitates and precipitation of new phases [2,3]. Carbides tend to coagulate within the boundaries of ferrite grains, combine into long solid compounds with clearly visible grain boundaries, meanwhile no fine, dispersive carbides are encountered [4]. With aging, the carbides within the grain interior are slowly transformed into $\mathrm{M}_{23} \mathrm{C}_{6}$ type of carbides [5]. 
During operation at high temperature, $\mathrm{Fe}$ in the $\mathrm{M}_{23} \mathrm{C}_{6}$ carbide lattice is replaced by $\mathrm{Cr}$ and Mo because of diffusion of alloying elements from the matrix. Chromium and molybdenum have a larger atomic radius $(0.125$ $\mathrm{nm}$ and $0.135 \mathrm{~nm}$, respectively) than iron $\left(0.24 \mathrm{~nm}\right.$ ) [6] so migration of these elements causes $\mathrm{M}_{23} \mathrm{C}_{6}$ carbide lattice expansion. Lattice expansion is more affected by Mo because of a larger atomic radius compared to $\mathrm{Fe}$ and $\mathrm{Cr}$ atoms which have close atomic numbers [7].

In the $9 \% \mathrm{Cr}$ steel, the $\mathrm{Cr}$ and Mo content increased due to diffusion of those elements after $100000 \mathrm{~h}$ at $600^{\circ} \mathrm{C}[8,9]$. X-ray spectroscopy (EDX) analysis of $\mathrm{M}_{23} \mathrm{C}_{6}$ precipitates showed that the ratio $\mathrm{Cr} / \mathrm{Fe}$ continuously increases with heat treatment duration towards attaining the stable $\mathrm{M}_{23} \mathrm{C}_{6}$ [10]. Our previous research [11] has shown that within a certain range of aging time the $\mathrm{M}_{23} \mathrm{C}_{6}$ carbide lattice parameter value in $\mathrm{P} 91$ steel increases linearly when plotted on a natural logarithmic scale. The equation was derived for calculation of $\mathrm{M}_{23} \mathrm{C}_{6}$ lattice parameter value depending on the aging time at a given temperature. It was suggested that lattice parameter changes could be used as an indicator for the assessment of the actual thermal aging duration of heat resistant steel.

Structural changes in P91 steel have been extensively studied, however, there are few publications on $5 \% \mathrm{Cr}$ steel aging. The present work aims to investigate the migration of the alloying elements into $\mathrm{M}_{23} \mathrm{C}_{6}$ carbide lattice at elevated temperature for both P91 and P5 heat resistant steels aged under the same conditions and to examine the effect of different chromium content on the $\mathrm{M}_{23} \mathrm{C}_{6}$ carbide crystallographic structure changes.

\section{EXPERIMENTAL}

Heat resistant ferritic-martensitic steel P91 and P5 samples were aged in the electric furnace at $700{ }^{\circ} \mathrm{C}$ for a predetermined time. Temperature accuracy was maintained within $\pm 1^{\circ} \mathrm{C}$. The chemical composition of the investigated steel samples determined using Optical Emission Spectrometer Q4 Tasman is presented in Table 1.

Table 1 Chemical composition of P5 and P91 steel

\begin{tabular}{|l|l|l|l|l|l|l|l|l|l|l|l|l|}
\hline \multirow{2}{*}{$\begin{array}{l}\text { ASTM A335 } \\
\text { Steel:grade }\end{array}$} & \multicolumn{10}{|c|}{ Element concentration, wt \% } \\
\cline { 2 - 14 } & $\mathrm{C}$ & $\mathrm{Si}$ & $\mathrm{Mn}$ & $\mathrm{P}$ & $\mathrm{Cr}$ & $\mathrm{Mo}$ & $\mathrm{Ni}$ & $\mathrm{Cu}$ & $\mathrm{Al}$ & $\mathrm{N}$ & $\mathrm{Nb}$ & $\mathrm{V}$ \\
\hline P91 & 0.094 & 0.380 & 0.350 & 0.006 & 8.780 & 0.960 & 0.160 & 0.070 & 0.012 & 0.035 & 0.080 & 0.180 \\
\hline P5 & 0.095 & 0.356 & 0.492 & 0.020 & 5.008 & 0.458 & 0.098 & 0.102 & 0.014 & 0.014 & 0.008 & 0.015 \\
\hline
\end{tabular}

Microstructures of samples were analysed by a scanning electron microscope. A polished steel microstructure was revealed by Vilella's reagent. The microstructure of the as-received material is shown in Figure 1. The electrochemical extraction method was used to extract carbides from steel. Samples were etched in $5 \%$ hydrochloric acid solution at $80-100 \mathrm{~mA} / \mathrm{cm}^{2}$ current density for $8-10$ hours. The precipitates of carbide residues were washed in distilled water and dried at $95^{\circ} \mathrm{C}$.

The composition of extracted residues was analysed using a ZEISS EVO MA10 scanning electron microscope equipped with the Bruker XFlash 6/10 EDX detector. EDX measurements were performed on a residue powder distributed on a copper plate. Because of the small size of $\mathrm{M}_{23} \mathrm{C}_{6}$ carbide particles, their composition cannot be determined directly from the metallographic specimen, as $\mathrm{Cr}$ and $\mathrm{Fe}$ spectrum from carbide can overlap with the ones in the matrix.

The XRD analysis of carbides from the extracted residues of the as-received and thermally aged steel samples were recorded with the Bruker D8 Advance diffractometer in a Bragg-Brentano configuration. CuKa wavelength radiation (tube voltage of $40 \mathrm{kV}$ and current of $40 \mathrm{~mA}$ ) filtered with Ni 0.02 filter was used. Data were collected over the diffraction range $2 h=25-100^{\circ}$ with a step of $0.02^{\circ}$ and counting time of $96 \mathrm{~s}$ per step using a fast counting detector Bruker LynxEye and a coupled two theta/theta scan type. 

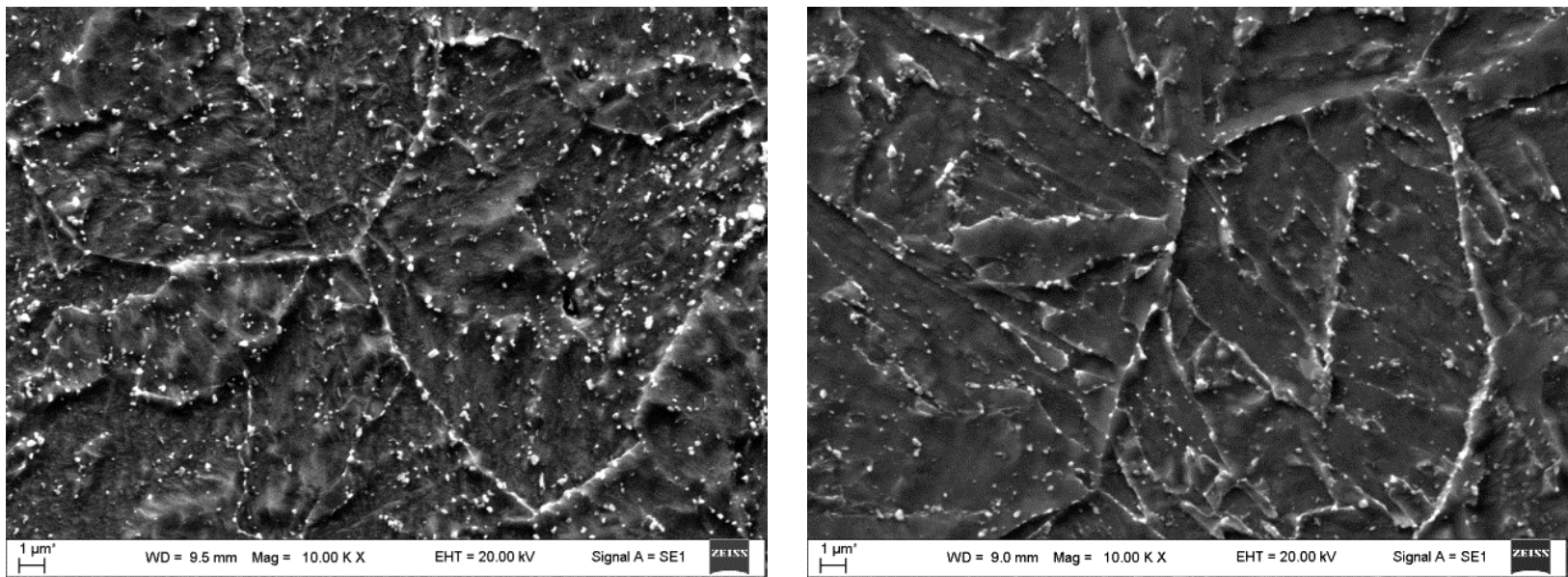

Figure 1 The scanning electron microscopy images of as-received P5 (left) and P91 (right) steel
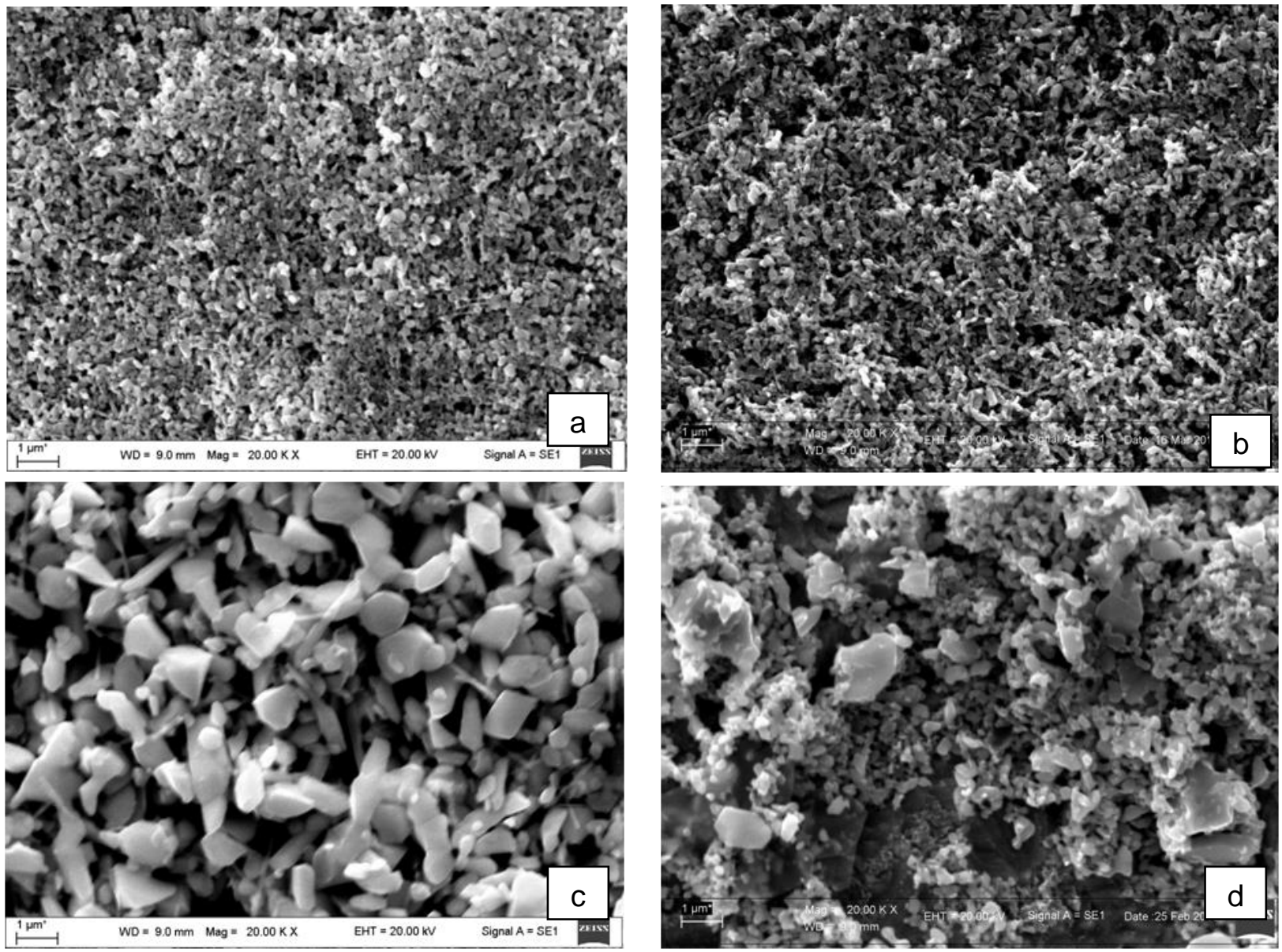

Figure 2 The scanning electron microscopy images of carbide precipitates: as-received P5 steel (a); after aging at $700^{\circ} \mathrm{C}$ for 53 days (c); as-received P91 steel (b), after aging at $700^{\circ} \mathrm{C}$ for 234 (d) days

\section{RESULTS AND DISCUSSION}

The microstructure is tempered martensite containing carbides and nitrides which are the strengthening precipitates. Our previous studies [11] by the X-ray diffraction and SEM/EDX revealed the presence of M23C6 carbides and $M X$ carbonitrides in as- received $\mathrm{P} 91$ steel and after thermal exposure. The $\mathrm{M}_{23} \mathrm{C}_{6}$ carbides for both P5 and P91 steel (Figure 1) are mainly located at prior austenite grain boundaries and along martensite 
lath boundaries, while the smaller MX carbides and carbonitrides are predominantly distributed within lath and grains. After aging at $700{ }^{\circ} \mathrm{C}$, the coarsening of $\mathrm{M}_{23} \mathrm{C}_{6}$ carbides occurs, mostly along grain and lath boundaries. The process of carbides coarsening at $700^{\circ} \mathrm{C}$ is particularly fast for the $\mathrm{P} 5$ steel (Figures $2 \mathrm{a}, \mathrm{c}$ ), but a slower coarsening process is observed in case of P91 steel (Figures 2, b, f).

Results of carbide $\mathrm{M}_{23} \mathrm{C}_{6}$ lattice parameter (a) measurements are shown in Figure 4, which indicates, that the value of parameter a increases with aging time duration. The $\mathrm{M}_{23} \mathrm{C}_{6}$ parameter a value for $\mathrm{P} 91$ changes in the first 40 days of aging then remains constant. The lattice expansion occurs due to the diffusion of alloying elements in the lattice of carbide. During this process, $\mathrm{Fe}$ atoms in carbide lattice were partly changed by $\mathrm{Cr}$ and $\mathrm{Mo}$, but as diffusion coefficient of $\mathrm{Cr}$ is higher than Mo, consequently $\mathrm{Cr}$ atoms dominate in the $\mathrm{M}_{23} \mathrm{C}_{6}$ lattice. In $\mathrm{P} 5$ steel, the $\mathrm{M}_{23} \mathrm{C}_{6}$ carbide lattice parameter increases in the first 5 days of aging then remain constant. The increase of $\mathrm{Mo}$ in $\mathrm{M}_{23} \mathrm{C}_{6}$ for $\mathrm{P} 5$ steel during the aging process is substantial and is the main reason for carbide lattice expansion.
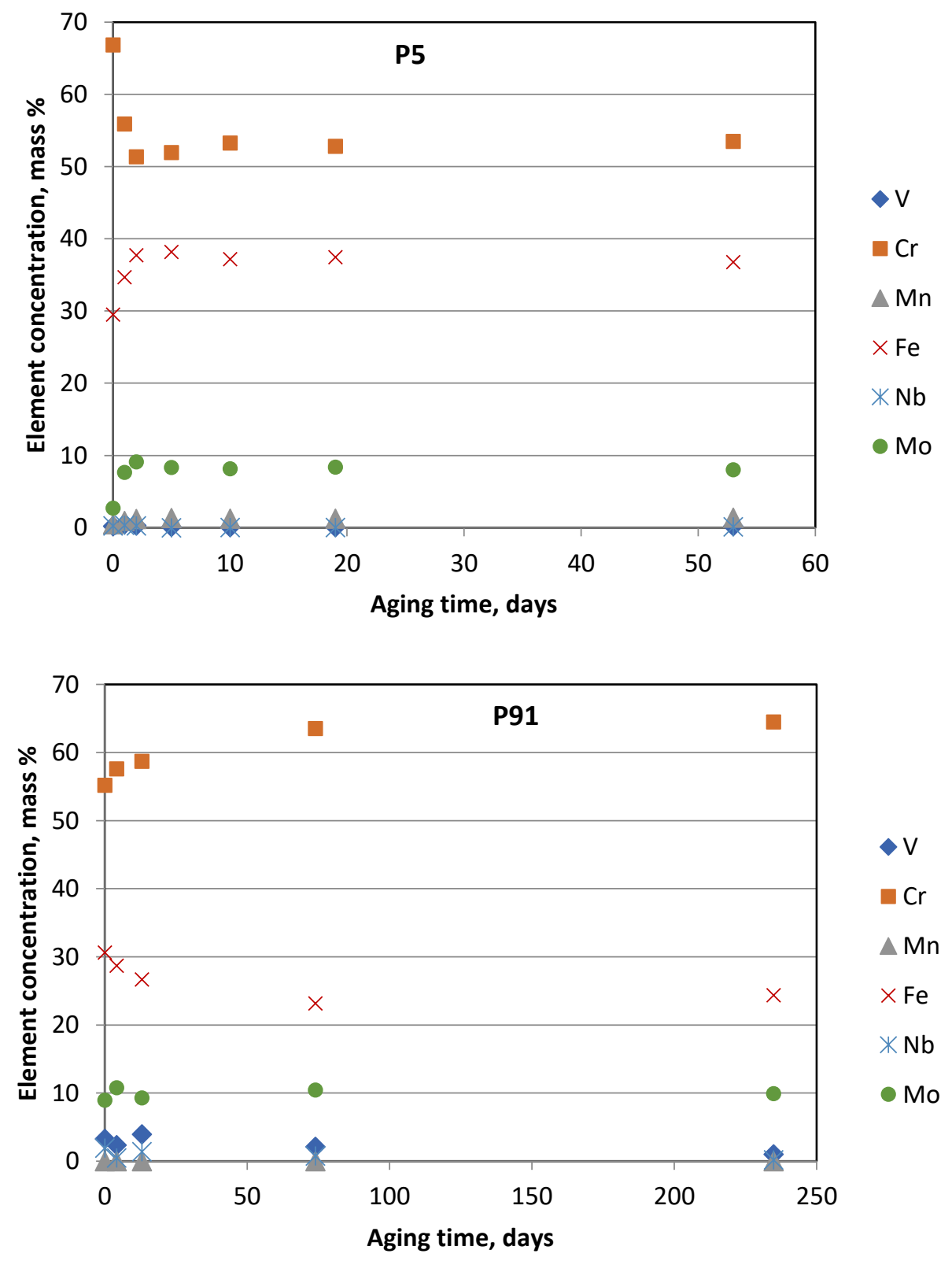

Figure 3 Changes in elemental composition of carbide precipitates in P5 and P91 steel depending on aging time at $700{ }^{\circ} \mathrm{C}$ 


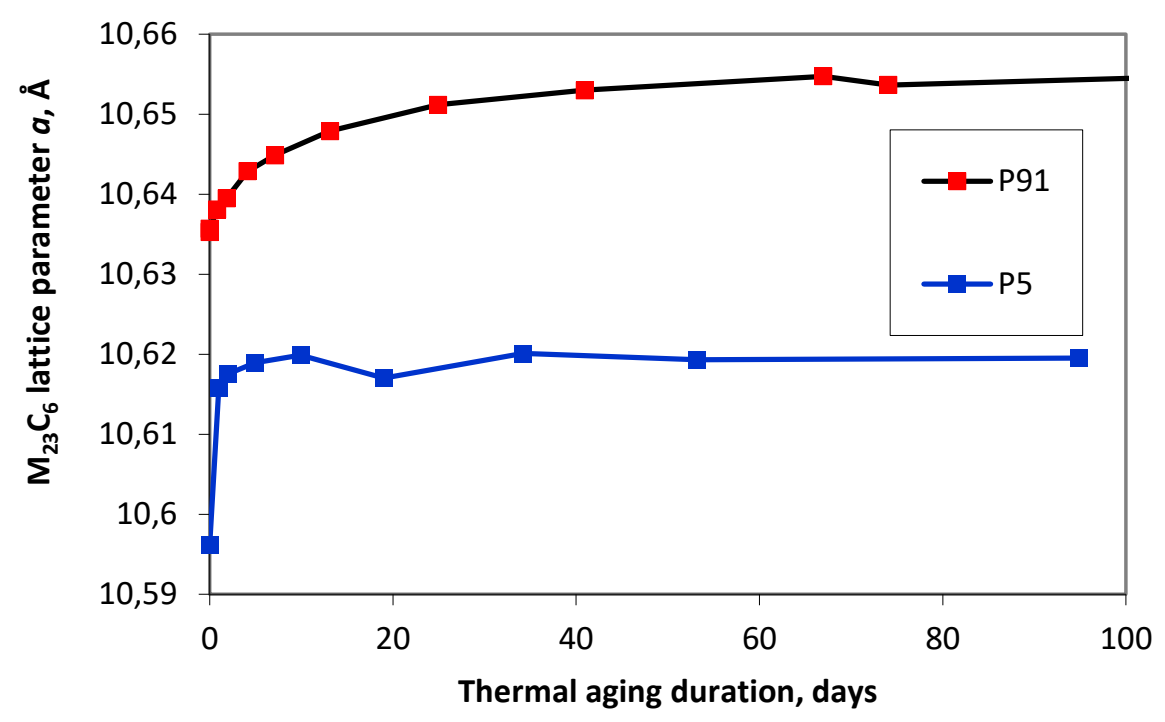

Figure 4 The changes of lattice parameter a of carbide $\mathrm{M}_{23} \mathrm{C}_{6}$ in $\mathrm{P} 5$ and $\mathrm{P} 91$ steel depending on aging time at $700{ }^{\circ} \mathrm{C}$

\section{CONCLUSION}

Electrochemically extracted carbides from P91 and P5 steel in as-received as well as in the exposed at $700^{\circ} \mathrm{C}$ conditions were characterized by SEM EDX and XRD analysis. $\mathrm{M}_{23} \mathrm{C}_{6}$ carbide is rich in $\mathrm{Cr}$ as a main phase and carbonitrides $\mathrm{M}(\mathrm{C}, \mathrm{N})$ rich in $\mathrm{V}$ and $\mathrm{Nb}$ as a minor phase were identified in P91 steel precipitates.

The chromium content in the $\mathrm{M}_{23} \mathrm{C}_{6}$ carbide lattice of $\mathrm{P} 91$ steel steadily increases. On the contrary, in the case of $\mathrm{P} 5$ steel, the $\mathrm{Cr}$ content decreases and reaches equilibrium after a short aging time. Meanwhile, although the molybdenum amount in the $\mathrm{M}_{23} \mathrm{C}_{6}$ increases marginally in the case of P91 steel, the increase of Mo in $\mathrm{M}_{23} \mathrm{C}_{6}$ of $\mathrm{P} 5$ steel is substantial. The lattice parameter in $\mathrm{M}_{23} \mathrm{C}_{6}$ determined using $\mathrm{x}$-ray diffraction increases in both P5 and P91 steel, but equilibrium is reached earlier in the case of P5 steel.

Obtained results could be useful for the evaluation of heat resistant steel and prediction of remaining operational life.

\section{REFERENCES}

[1] ZAVAletA GUtieRREZ, N., DE CICCO, H., MARRERO J., DANON, C.A., LUPPO, M.I. Evolution of precipitated phases during prolonged tempering in a $\% \% \mathrm{Cr} 1 \% \mathrm{MoVNb}$ ferritic-martensitic steel: Influence on creep performance. Materials Science and Engineering. 2011, vol. 528A, no. 12, pp. 4019-4029.

[2] PANAIT, C.G., BENDICK, W., FUCHSMANN, A., GOURGUES-LORENZON, A.-F., BESSON, J. Study of the microstructure of the Grade 91 steel after more than $100,000 \mathrm{~h}$ of creep exposure at $600^{\circ} \mathrm{C}$. International Journal of Pressure Vessels and Piping. 2010, vol. 87 (6), pp. 326-335.

[3] ALIPRANDI, P., GUGLIELMINO, E., SILI, A. Damage assessment of topping furnaces radiant tubes and creep behaviour of ASTM A335 P5 steel. Materials at High Temperatures. 2020, vol. 37, no. 2, pp. 81-88.

[4] KUMŠLYTIS, V., VALIULIS, V. A., ČERNAŠĖJUS, O. Effect of PWHT on the Mechanical Properties of p5 Steel Welded Joints. Solid State Phenomena. Trans Tech Publications Switzerland. 2010, vol.165, pp. $104-109$.

[5] KUMŠLYTIS, V., SKINDARAS, R.,. VALIULIS, A. V. The Structure and Properties of 5\% Cr-0.5\%Mo Steel Welded Joints after Natural Ageing and Post-weld Heat Treatment. Materials Science (Medžiagotyra). 2012, vol. 18, no. 2, pp. 119-122. 
[6] CARPENTER, S.D. CARPENTER, D. and PEARCE, J.T.H., XRD and electron microscope study of a heat treated 26.6\% chromium white iron microstructure. Materials Chemistry and Physics. 2007, vol. 101 (1), pp. 49-55.

[7] BALTUŠNIKAS, A., GRYBĖNAS, A., KRIUKIENE, R., LUKOŠIŪTĖ, I., MAKAREVIČIUS, V. Evolution of Crystallographic Structure of M23C6 Carbide under Thermal Aging of P91 Steel. Journal of Materials Engineering and Performance. 2019, vol. 28, pp. 1480-1490.

[8] PANAIT, C.G., ZIELINSKA-LIPIEC, A., KOZIEL, T., CZYRSKA-FILEMONOWICZ, A., GOURGUES-LORENZON, A.F., BENDICK, W. Evolution of dislocation density, size of subgrains and MX-type precipitates in a P91 steel during creep and during thermal ageing at $600^{\circ} \mathrm{C}$ for more than $100,000 \mathrm{~h}$. Materials Science and Engineering. 2010, vol.527A, no. 16-17, pp. 4062-4069.

[9] SPIGARELLI, S. Microstructure-based assessment of creep rupture strength in $9 \mathrm{Cr}$ steels. International Journal of Pressure Vessels and Piping. 2013, vol.101, pp. 64-71.

[10] THOMAS PAUL, V., SAROJA, S., and VIJAYALAKSHMI, M. Microstructural stability of modified 9Cr-1Mo steel during long term exposures at elevated temperatures. Journal of Nuclear Materials. 2008, vol.378, no. 3, pp. 273281.

[11] BALTUŠNIKAS, A., LUKOŠIŪTĖ, I., MAKAREVIČIUS, V., KRIŪKIENĖ, R., GRYBE்NAS, A. Influence of thermal exposure on structural changes of M23C6 carbide in P91 steel. Journal of Materials Engineering and Performance. 2016, vol. 25 (5) pp. 1945-1951.

[12] CAI, G.J., ANDREN, H.O., SVENSSON, L.E. Microstructural change of a $5 \% \mathrm{Cr}$ steel weld metal during tempering. Materials Science and Engineering. 1998, vol. 242A, pp.202-209. 